\title{
Experimental Prediction of Hourly Diffuse Solar Radiation with Clearness Index in Baghdad (Iraq)
}

\author{
Hussein M. Taqi Al-Najjar \\ Lecturer at University of Baghdad \\ College of Engineering \\ Energy Engineering Department
}

\author{
Akram A. Abbood Al-Khazzar \\ Independent Researcher, \\ Former engineer at University of Baghdad, \\ College of Engineering, \\ Energy Engineering Department
}

\begin{abstract}
Design and simulation of solar energy installations need hourly data of diffuse and beam radiation components for assessing the dynamic behavior of those systems. However, the most widely available data is the global solar radiation. Whereas, diffuse and beam data are not readily affordable. Thus, numerous empirical models of correlations were developed at different sites in the world to predict the required radiation components. In the present paper, an hourly correlation expressed in a third-degree polynomial relating the diffuse fraction with the clearness index was developed based on field measurements of global and diffuse solar radiations in Baghdad city $\left(33.33^{\circ} \mathrm{N}\right)$, Iraq. The validation and accuracy of the developed correlation was evaluated using six widely used statistical parameters. Among these parameters, the values of linear coefficient of correlation, mean percentage error and root mean square error were found to be $0.885,6.24 \%$ and $8.0 \%$ respectively which indicates good performance. In addition, eight different empirical diffuse models for various sites were chosen from the literature for statistical comparison with the developed correlation in this study. The best model was that of South America at site latitude $23.56^{\circ} \mathrm{S}$ with mean percentage error $16 \%$ and root mean square error $11.5 \%$ which shows the largest agreement. A computer program was established for generating the necessary data for developing the required correlation and also for calculating the essential statistical evaluations and comparisons in the present work.
\end{abstract}

\section{Keywords}

hourly diffuse fraction, clearness index, empirical models, statistical parameters, Baghdad (Iraq).

\section{INTRODUCTION}

Recently, the global tendency is to use various utilizations of renewable energy resources like solar, wind, biomass and tidal to generate energy for different applications [1]. Solar energy can play an important role with many advantages such as high abundance and diversity of output energy (electric and thermal) that can be employed in industry and buildings with arrays of solar collectors [2-5].

The performance of solar energy installations: photovoltaic, thermal or hybrid, flat or concentrating, fixed or movable, is usually analyzed on hourly, daily and monthly basis. This in turn requires associated solar radiation data which consists of two components: beam and diffuse. However, direct measurements of the radiation components are not readily affordable for long time periods at all interested locations in the world [6]. Alternatively, numerical techniques of estimation could be employed in order to find these components based on the most readily observed data: global solar radiation and atmospheric conditions. Following the pioneer work of Liu and Jordan [7] on this issue, numerous researchers had developed various diffuse-estimation models for different geographic locations and climate environments around the world.

Wong and Chow [8] reviewed two categories of such estimation models: parametric models using detailed meteorological parameters and decomposition models as correlations based on global radiation measurements. Two parametric models and eleven empirical correlations were presented from the literature and used for comparison with measured data for Hong Kong [8].

A very recent paper of Khorasanizadeh and Mohammadi [9] classified and reviewed both daily and monthly mean daily diffuse solar radiation correlations that have been established for many locations during the past sixty years. The classification of [9] was based on the type of the parameters utilized in the correlations and the form of the function employed which gave 56 different models. The authors of [9] had grouped the parameters into: clearness index, relative sunshine duration, cloud cover rank (0-8), ambient temperature, relative humidity and others; while the groups of functional forms of correlations were: polynomial, rational and exponential. As indicated by [9], diffuse fraction is strongly correlated to clearness index in a polynomial form which has a great feature that only measured global solar radiation is required for applying such correlations.

Hourly diffuse correlations are of more importance since they are needed for the dynamic behavior of solar energy installations especially in design and simulation. Many hourly diffuse fraction correlations with clearness index were developed for Australia, Canada, USA, Europe, India, Hong Kong, North Mediterranean Area, Singapore, Brazil and Cyprus [10-21]. Several of these correlations are to be used in the present study.

For Iraq, to the best knowledge of the authors, no previously published work was found for an hourly diffuse correlation based on experimental data. The present paper aims to predict the hourly diffuse solar radiation in Baghdad city, Iraq by developing a polynomial correlation of diffuse fraction with clearness index based on field measurements data with good statistical performance. In addition, the paper is to find an empirical model, among the different correlations in previously published literature, which is of best statistical agreement with the local developed correlation in this study.

\section{SOLAR RADIATION: COMPONENTS AND CLEARNESS INDEX}

The amount of hourly solar radiation on the surface of a given solar array, $I_{S}\left(\mathrm{~J} / \mathrm{m}^{2}\right)$ is found as [22]:

$I_{s}=I_{b} R_{b}+I_{d}\left(\frac{1+\cos \beta}{2}\right)+I \rho_{g}\left(\frac{1-\cos \beta}{2}\right)$ 
Where $I_{b}$ and $I_{d}$ are the beam and diffuse components of the global radiation $I\left(\mathrm{~J} / \mathrm{m}^{2}\right), \beta$ is the slope of the surface, $\rho_{g}$ is the reflectance of the surroundings and $R_{b}$ is the geometric factor for beam radiation which depends on the surface orientation with respect to the line to the sun. A clearness index $k_{t}$ (ratio of global-to-extraterrestrial radiation) is introduced as a measure of the transmittance of the atmosphere $\left(0<k_{t}<1\right)$, then [23]:

$k_{t}=\frac{I}{I_{o}}$

Where $I_{o} \quad\left(\mathrm{~J} / \mathrm{m}^{2}\right)$ is the extraterrestrial solar radiation on horizontal surface and calculated by [22]:

$I_{o}=G_{s c}\left(1+0.033 \cos \frac{360 n}{365}\right)(\cos \varphi \cos \delta \cos \omega$
$+\sin \varphi \sin \delta)$

Where $G_{s c}$ is the solar constant $\left(1367 \mathrm{~W} / \mathrm{m}^{2}\right), n$ is the number of the day in the year, $\varphi$ is the site latitude, $\omega$ is the hour angle (one degree of hour angle corresponds to four minutes of solar time) and $\delta$ is the solar declination angle as given by [22]:

$\delta=23.45^{\circ} \sin \left[\frac{360}{365}(n+284)\right]$

Now, since global solar radiation $I$ is the only readily measured data, then the diffuse fraction $k_{d}$ (ratio of diffuseto-global radiation) is to be found as a polynomial function with the clearness index $k_{t}$ as:

$k_{d}=f\left(k_{t}\right)$

Where the diffuse fraction is

$k_{d}=\frac{I_{d}}{I}$

\section{EXPERIMENTAL WORK}

Global solar radiation I (beam plus diffuse) is usually measured on a horizontal surface using simple detectors called pyranometers, while beam radiation needs more sophisticated instruments using collimated detectors called pyrheliometers which measures the beam radiation at normal incidence, $I_{b n}$. Pyrheliometers require additional setups for sun tracking to keep normal position. On the other hand, for diffuse radiation measurement $I_{d}$ on a horizontal surface, the simple pyranometer can be used by blocking the beam radiation. The most common blocking device is a shadow band that is composed of a ring or disc arranged to shade the detector from beam radiation. In this case, a pyranometer will measure the diffuse radiation only [24-26].

Because of simplicity, the shadow band devices cost much less than other more sophisticated devices. In literature [19, 21, 27-29], many studies had implemented the same shadow band device to experimentally split the diffuse radiation from global solar radiation.

In the present work, the shadow band device is constructed of a black plastic semi-circle band of $70 \mathrm{~cm}$ diameter and $10 \mathrm{~cm}$ width. The band is fixed around the solar meter TES-133 which is placed right at the center of the circle. The band is screwed to movable steel bars to track the sun about the polar axis of the sun path [30]. To get a reading, the band is shifted till the lens of the solar meter is completely shaded by the band. Each reading is to be corrected according to Coulson [31] by a factor between 1.05 to 1.25 based on some assumptions of diffuse radiation distribution over the sky as a function of site latitude and date.

\section{DATA AND METHODOLGY}

For developing an experimentally diffuse model for Eqn (5) that can predict the hourly diffuse solar radiation in Baghdad city $\left(33.33^{\circ} \mathrm{N}\right)$, Iraq, the required radiation data were gathered by field measurements at the Solar Energy Laboratory of energy engineering department in the college of engineering, Baghdad/ Al-Jadriya. The measured data include global and diffuse radiation, using the techniques explained in section 3 , at random hours for a period of six months: April - September 2015. The data set of diffuse fraction $k_{d}$ and clearness index $k_{t}$ was generated using a computer program that was established for the present work according to the equations of section 2 and the field data. In addition, for comparison with the locally developed correlation in this paper, eight empirical hourly-diffuse models were selected from previously published works for different locations around the world. These models are presented as follows:

Model 1: Orgill and Hollands [11]:

$$
\begin{array}{ll}
k_{t}<0.35 ; & k_{d}=1-0.249 k_{t} \\
0.35 \leq k_{t} \leq 0.75 ; & k_{d}=1.557-1.84 k_{t} \\
k_{t}>0.75 ; & k_{d}=0.177
\end{array}
$$

Model 2: Reindl et al. [13]:

$$
\begin{array}{ll}
k_{t} \leq 0.3 ; & k_{d}=1.02-0.248 k_{t} \\
0.3<k_{t}<0.78 ; & k_{d}=1.45-1.67 k_{t} \\
k_{t} \geq 0.78 ; & k_{d}=0.147
\end{array}
$$

Model 3: Chandrasekaran and Kumar [15]:

$k_{t} \leq 0.24 ; \quad k_{d}=1.0086-0.178 k_{t}$

$0.24<k_{t} \leq 0.8 ; \quad k_{d}=0.9686+0.1325 k_{t}+$ $1.4183 k_{t}{ }^{2}-10.1860 k_{t}{ }^{3}+8.3733 k_{t}{ }^{4}$

$k_{t}>0.8 ; \quad k_{d}=0.197$

Model 4: Lam and Li [16]:

$k_{t} \leq 0.15 ; \quad k_{d}=0.977$

$0.15<k_{t} \leq 0.7 ; \quad k_{d}=1.237-1.361 k_{t}$

$k_{t}>0.7 ; \quad k_{d}=0.273$

Model 5: Miguel et al. [17]:

$k_{t} \leq 0.21 ; \quad k_{d}=0.995-0.081 k_{t}$

$0.21<k_{t} \leq 0.76 ; \quad k_{d}=0.724+2.738 k_{t}-8.32 k_{t}{ }^{2}+$ $4.967 k_{t}^{3}$

$k_{t}>0.76$;

$k_{d}=0.18$

Model 6: Hawlader [18]:

$k_{t}<0.225$;

$k_{d}=0.915$

$0.225 \leq k_{t} \leq 0.775 ; \quad k_{d}=1.1389-0.9422 k_{t}-$ $0.3878 k_{t}^{2}$

$k_{t}>0.775$;

$k_{d}=0.215$

Model 7: Soares et al. [20]:

$k_{t} \leq 0.17$

$k_{d}=1$

$0.17<k_{t}<0.75 ; \quad k_{d}=0.9+1.1 k_{t}-4.5 k_{t}^{2}+$

$0.01 k_{t}^{3}+3.14 k_{t}^{4}$

$k_{t} \geq 0.75$;

$k_{d}=0.18$

Model 8: Jacovides et al. [21]: 
$k_{t} \leq 0.1 ; \quad k_{d}=0.987$

$0.1<k_{t} \leq 0.8 ; \quad k_{d}=0.94+0.937 k_{t}-5.01 k_{t}^{2}+$

$3.32 k_{t}^{3}$

$k_{t}>0.8 ; \quad k_{d}=0.177$

Table 1 lists the above selected models used in the study with their degree of polynomials and corresponding locations.

\section{STATISTICAL PERFORMANCE}

There are six widely used parameters for testing the statistical performance of a model. These are: linear coefficient of correlation, $r$, mean bias error (MBE), mean percentage error (MPE), root mean square error (RMSE), mean absolute bias error (MABE) and mean absolute percentage error (MAPE). The corresponding equations are given by [32]:

$r=\frac{N \sum x_{i} y_{i}-\sum x_{i} \sum y_{i}}{\sqrt{N \sum x_{i}{ }^{2}-\left(\sum x_{i}\right)^{2}} \sqrt{N \sum y_{i}{ }^{2}-\left(\sum y_{i}\right)^{2}}}$

$M B E=\frac{1}{N} \sum_{i=1}^{N}\left(y_{i}-x_{i}\right)$

$M P E=\frac{1}{N} \sum_{i=1}^{N} \frac{\left(y_{i}-x_{i}\right)}{x_{i}}$

$R M S E=\left(\frac{1}{N} \sum_{i=1}^{N}\left(y_{i}-x_{i}\right)^{2}\right)^{1 / 2}$

Here, $x_{i}$ is i-th observed value of diffuse fraction, $y_{i}$ is i-th predicted value of diffuse fraction and $N$ is the number of data.

The other two parameters, MABE and MAPE, are calculated by summing the absolute values in Eqn (16) and Eqn (17) respectively. As the value of $r$ approaches unity, it shows perfect relationship between predicted and observed data. The short-term and long-term performance of a model is given by the RMSE and MBE respectively. In fact, the MBE shows the average amount of overestimation in the model. Whereas, the MABE and MAPE values are indications of the goodness of the model. For the relative error, a value of MPE within $\pm 10 \%$ is considered acceptable.

In the present work, the above six statistical parameters were applied for two cases: (1) to evaluate the validation and accuracy of the developed diffuse correlation against measured data and (2) for comparison of selected models (M1 to M8) against the developed correlation. All statistical calculations for evaluation and comparison were carried out using the computer program that was established for this work.

\section{RESULTS AND DISCUSSION}

According to field measured data, the best fit diffuse fraction correlation with clearness index using Excel program was found to be of a third-degree polynomial:

$$
k_{d}=1.5973-4.6603 k_{t}+5.719 k_{t}^{2}-2.5719 k_{t}^{3}
$$

for $k_{t} \geq 0.20$. Fig 1 plotted the developed correlation along with the field data. About $71 \%$ of the radiation data for the corresponding period of April - September fall in the higher range of clearness index $k_{t} \geq 0.5$.

The statistical evaluation of Eqn (19) is presented in Table 2 with maximum individual values shown between parentheses.
The value of linear coefficient of correlation, $r$ is only $11.5 \%$ down from the perfect value. The long-term performance of the correlation is excellent with negligible average of overestimation since the MBE value $(0.005 \%)$ is very close to zero. The RMSE value is $8.0 \%$ which indicates a fairly good short-term performance. For the relative error, the obtained value of MPE $(6.24 \%)$ is considered small as it is less than the acceptable limit of $10 \%$. The goodness of the correlation equation (19) as indicated by the MABE value $(6.20 \%)$ is high. However, the MAPE value of $21.44 \%$ is somewhat large due to very scattered data. The forgoing statistical results proved that the developed diffuse correlation exhibits good overall performance.

For comparison, the selected empirical models (M1 to M8) and the present model are drawn together in Fig 2. It can be noticed that there is significant disagreement among the various correlations. This disagreement is more obvious in Fig 3 which displays the values of the six parameters for the statistical comparison. The divergence in performance could be due to different geographic locations, climate conditions and measuring instruments of the various models. The best and worst statistical parameters of the comparison are given in Table 3. The model for Hong Kong (M4: Lam and Li [16]) was the worst with respect to values of relative errors: MPE and MAPE (45.8\%). While the model for Canada (M1: Orgill and Hollands [11]) has the worst MBE and RMSE values (13.6\% and $19.0 \%$ respectively). On the other hand, five of the statistical parameters of the model for Sao Paulo, $23.56^{\circ} \mathrm{S}$ (M7: Soares et al. [20]) had the best values which indicates the largest agreement with the present correlation for Baghdad. The two correlations are drawn in Fig 4 which shows larger differences for clearness index $0.3<k_{t}<0.5$.

\section{CONCLUSION}

In the present paper, an hourly diffuse fraction correlation with clearness index was developed for Baghdad city based on 6-month field measured data. The predicted values of the correlation were evaluated against the field data. No previously published work was found for an hourly diffuse correlation for Iraq based on experimental data. In addition, eight hourly diffuse models for different locations around the world were selected from literature; see Table 1, for comparison with the present correlation of the study. Comprehensive evaluations and comparisons were carried out using six statistical tests: r, MBE, MABE, MPE, MAPE and RMSE. On the basis of this work, the following findings and conclusions can be stated:

- The obtained correlation is found to be as Eqn (19)

$k_{d}=1.5973-4.6603 k_{t}+5.719 k_{t}{ }^{2}-2.5719 k_{t}{ }^{3}$

with good overall performance in terms of validation and accuracy of the developed model, see Table 2.

- The above correlation equation can be used, in the absence of measured data, to compute the hourly diffuse and beam radiation components which are needed for design and simulation of different solar energy installations.

- The developed correlation is simply utilized since the only required data is the global solar radiation which can readily be measured.

- The clearness index is found to be an important atmospheric factor that is closely correlated to the diffuse 
fraction. Higher diffuse fraction is associated with lower clearness index and vice versa.

- The best application of the developed correlation is for summer months (of Baghdad city) which belong to the period of field data. Long-term solar field measurements are to be conducted to develop other hourly diffuse models with improved generalization.

- The comparison results indicated considerable disparity among the various correlations that is mainly due to different geographic locations. However, all of the widely selected diffuse models gave average overestimation of different amounts particularly in the middle range of clearness index. This means that
Baghdad city has higher beam radiation component which favoring the use of concentrating solar systems.

- Finally, the statistical comparison revealed the best and worst diffuse models, see Table 3 , in regard to the locally developed correlation in this work. The model for Sao Paulo city, Brazil (M7:Soares et al. [20]) was found to be of the best agreement as given by Eqn (13b):

$$
k_{d}=0.9+1.1 k_{t}-4.5 k_{t}{ }^{2}+0.01 k_{t}{ }^{3}+3.14 k_{t}{ }^{4}
$$

Whereas, the worst models were those for Hong Kong (M4:Lam and $\mathrm{Li}[16]$ ) and for Canada (M1:Orgill and Hollands [11]).

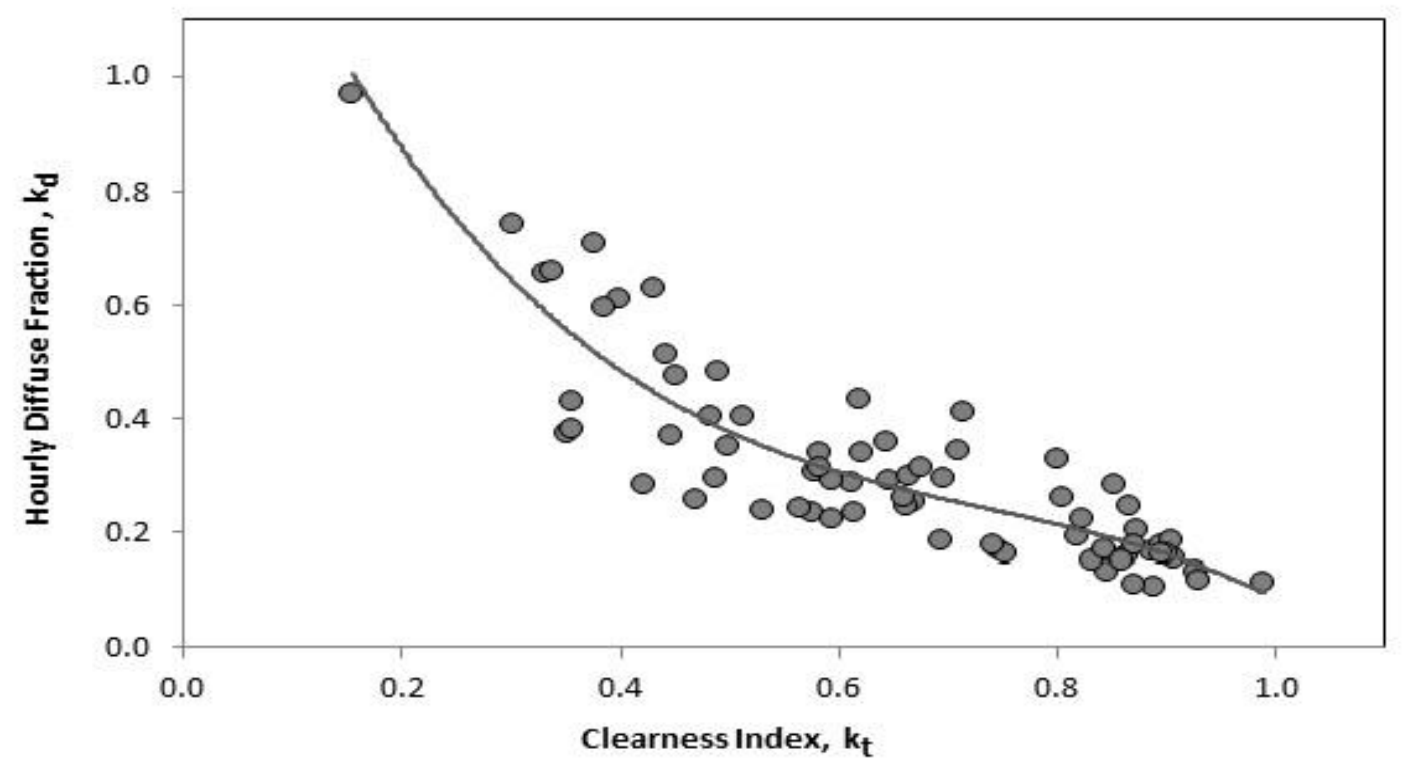

Fig 1: Hourly diffuse fraction with clearness index for the measured data and the developed correlation in the study.

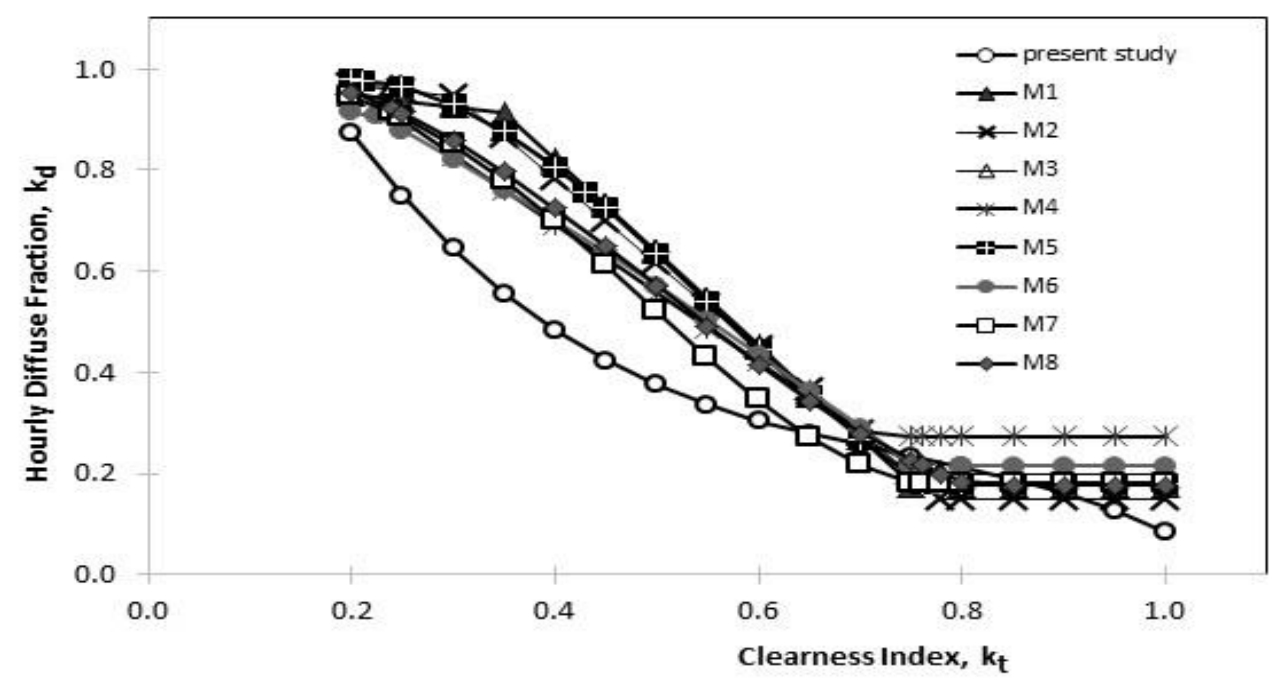

Fig 2: Hourly diffuse fraction with clearness index for the selected models and the developed correlation in the study. 


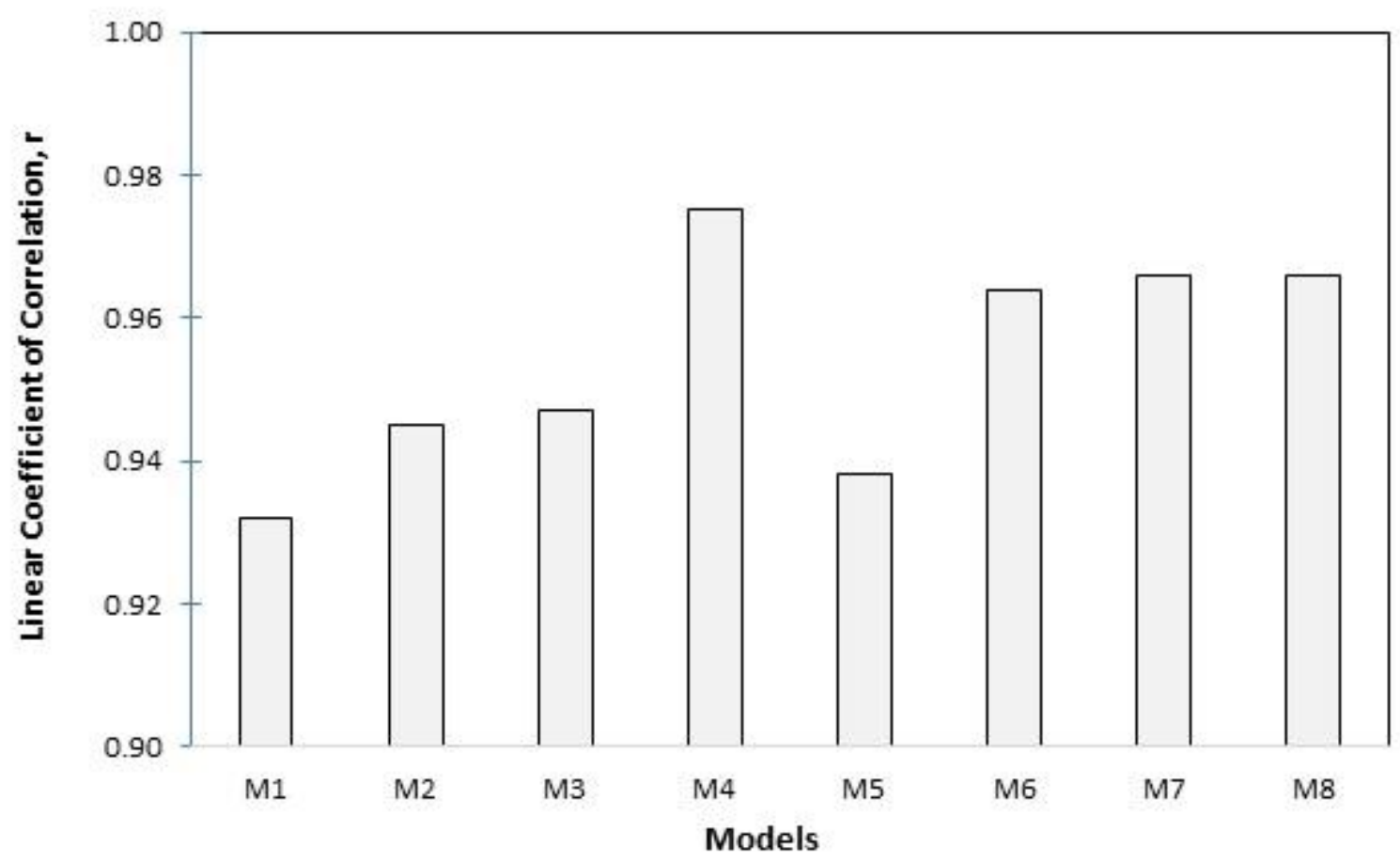

(a) Linear coefficient of correlation, $r$.

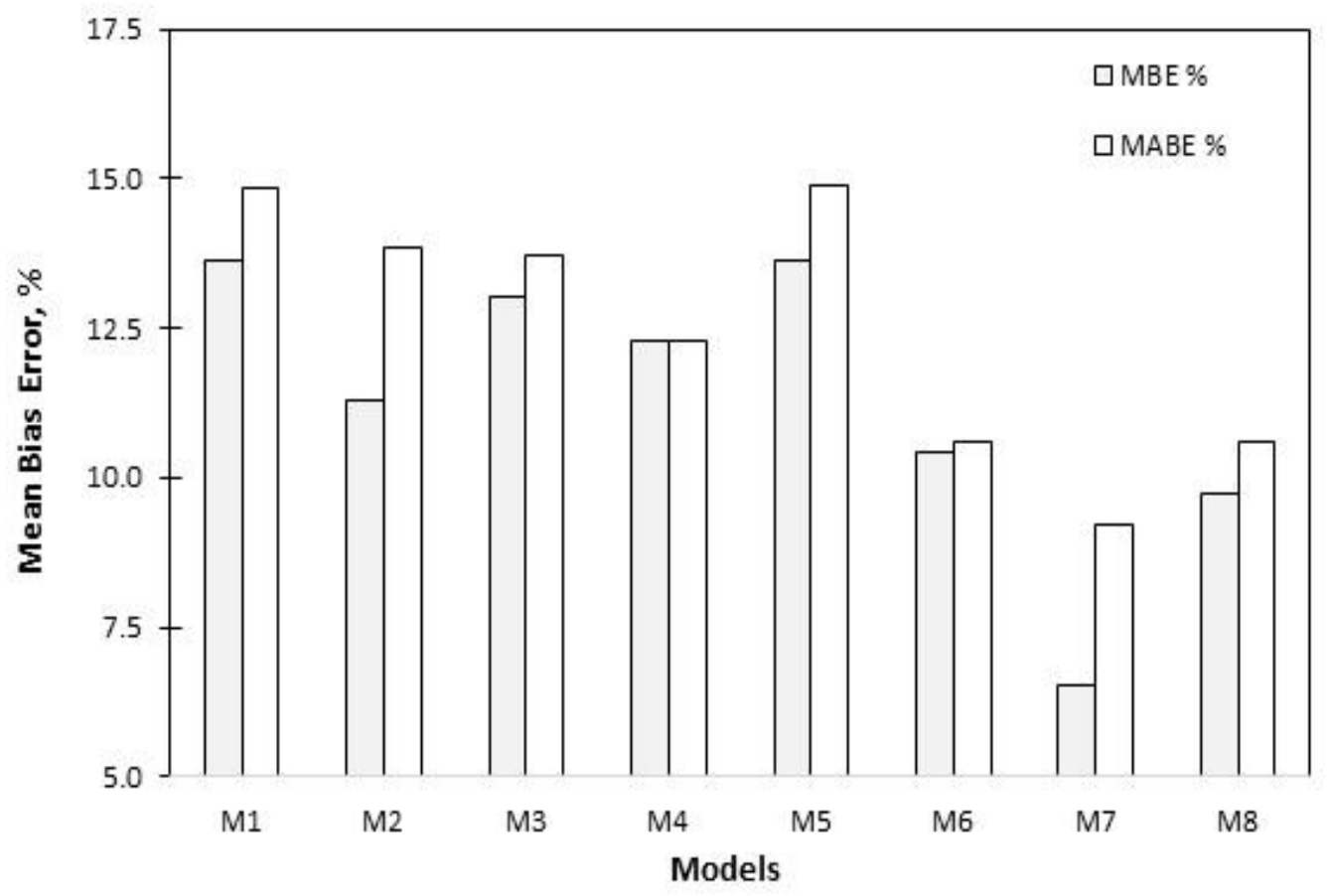

(b) MBE and MABE. 


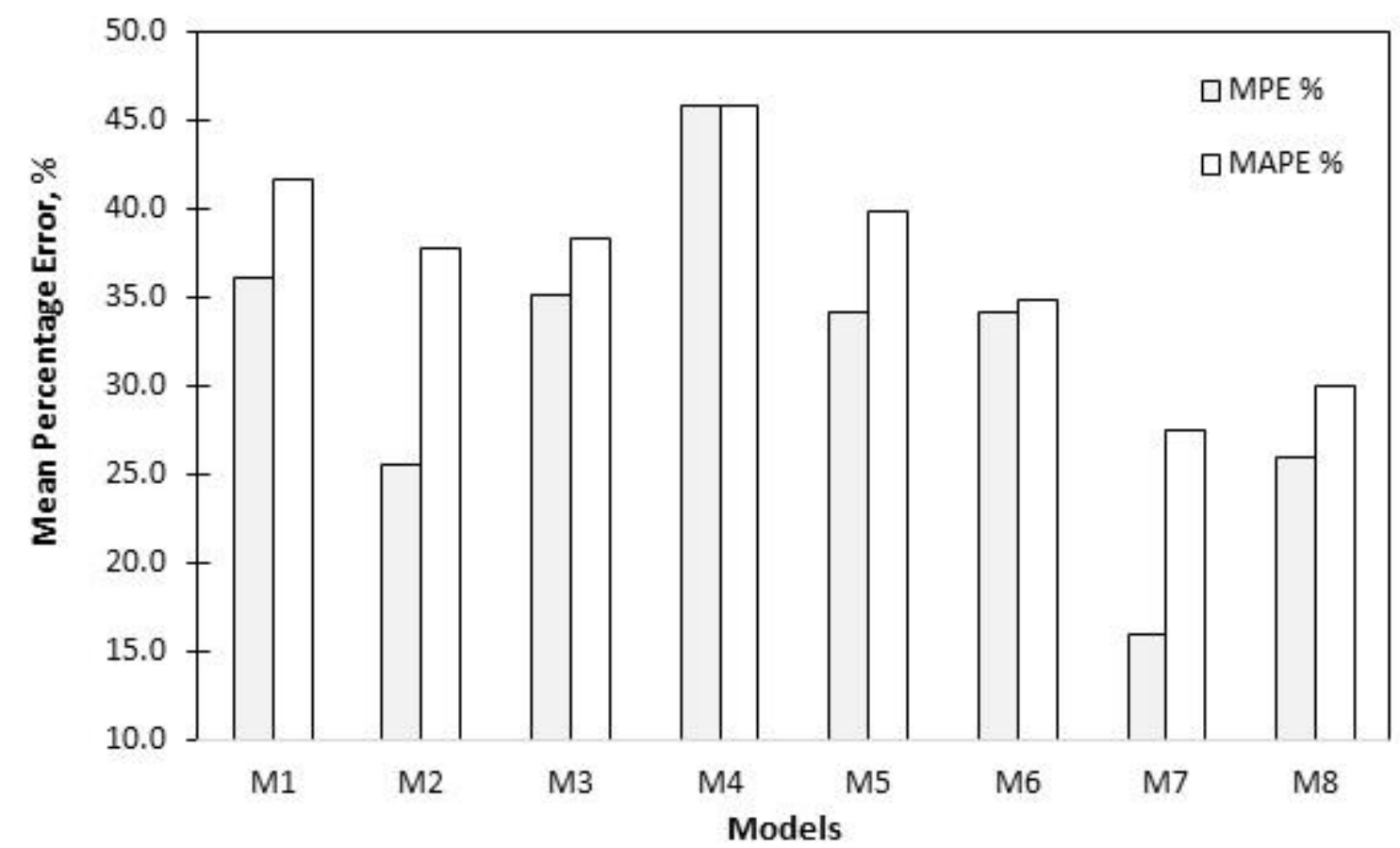

(c) MPE and MAPE.

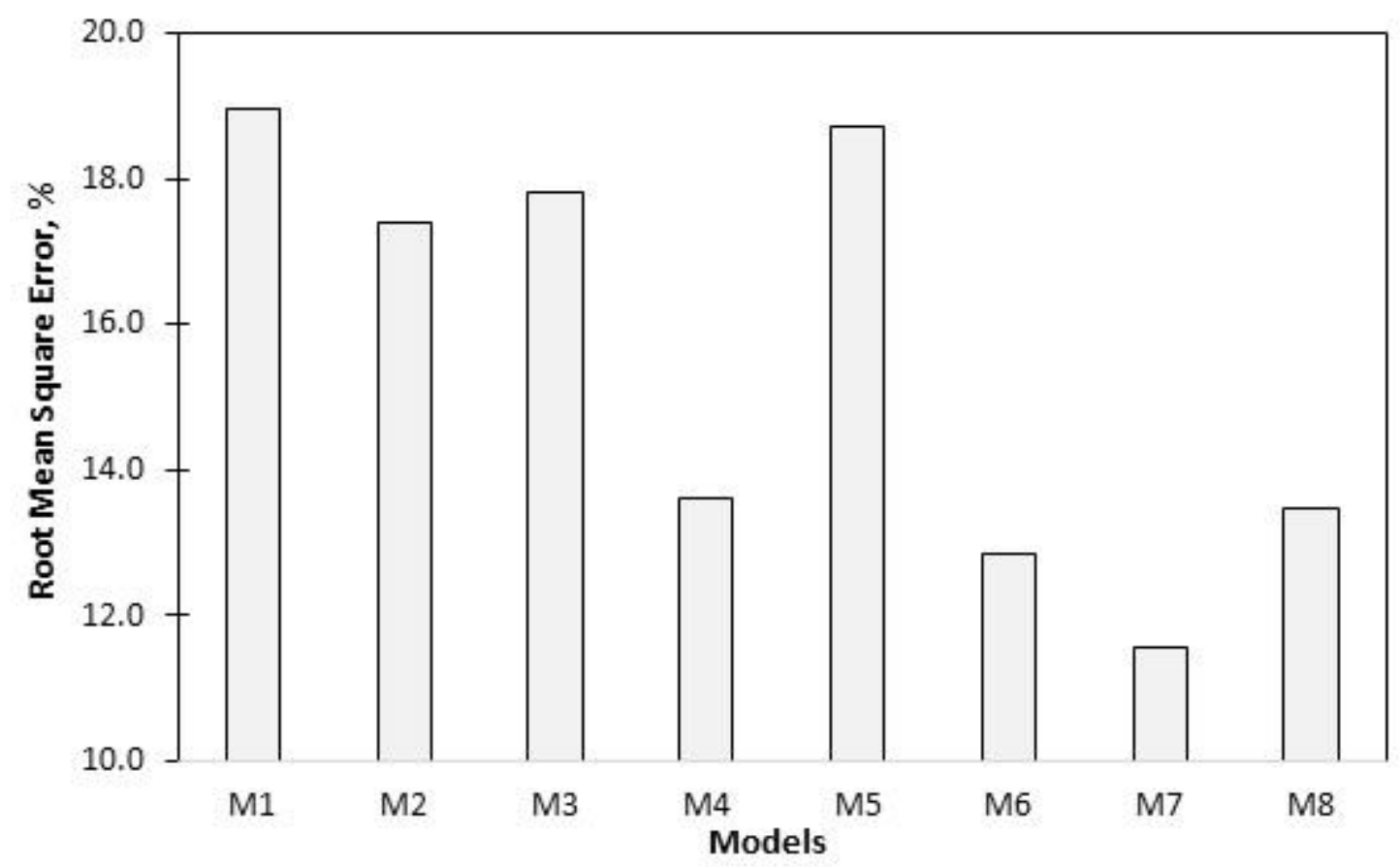

(d) RMSE.

Fig 3: Statistical parameters of comparison for the selected models with the developed correlation in the study:

(a) r (b) MBE \& MABE (c) MPE \& MAPE (d) RMSE. 


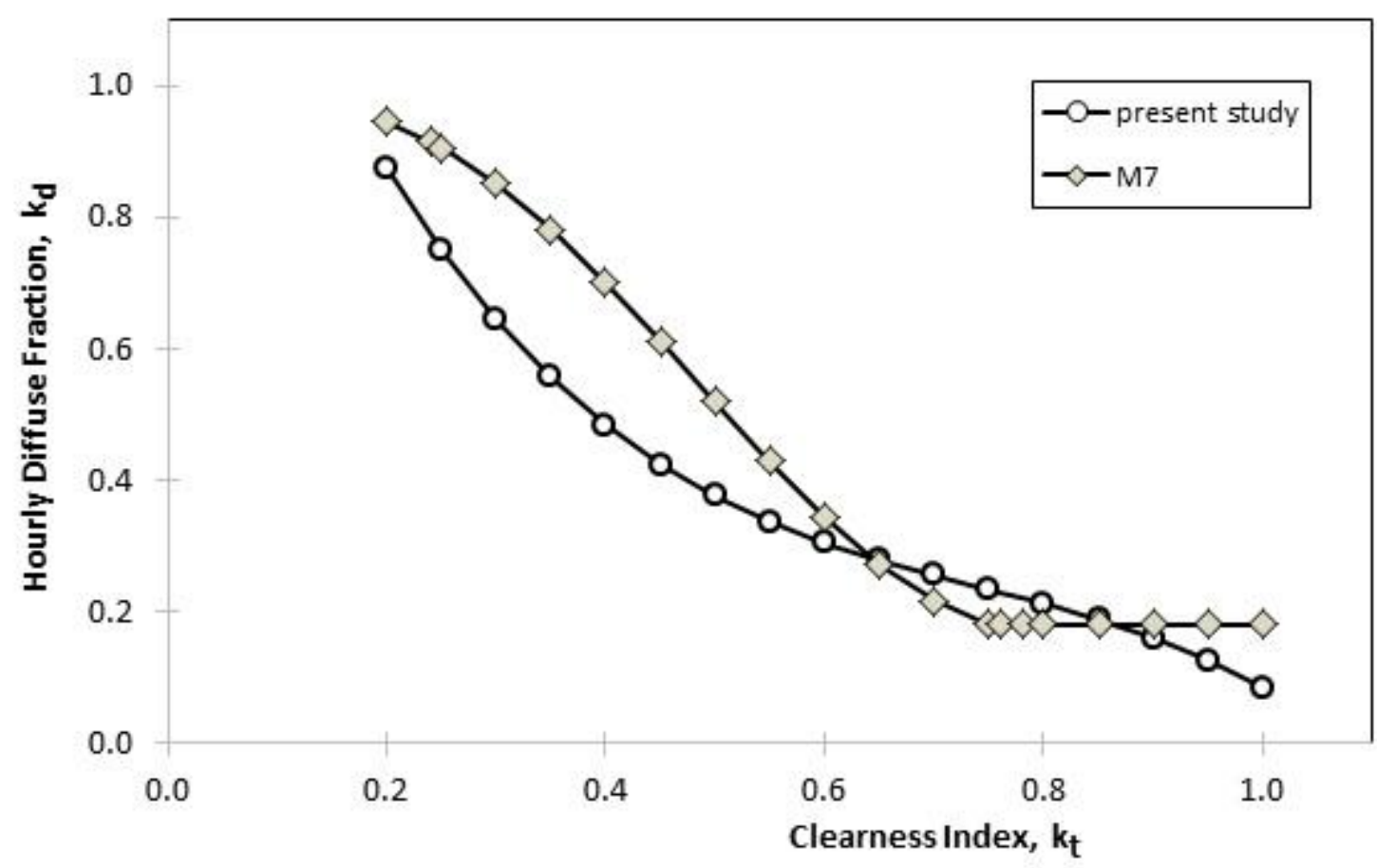

Fig 4: Hourly diffuse fraction with clearness index for M7 and the developed correlation in the study.

Table 1. List of selected models used in the study.

\begin{tabular}{|c|c|c|c|c|}
\hline Models & Degree & Authors & Date & Locations \\
\hline M1 [11] & $1^{\text {st }}$ & $\begin{array}{l}\text { Orgill and } \\
\text { Hollands }\end{array}$ & 1977 & Toronto airport, Canada. \\
\hline M2 [13] & $1^{\text {st }}$ & Reindl et al. & 1990 & $\begin{array}{l}5 \text { locations in the USA and Europe, USA: Alban! } \\
\text { \& Cape Canaveral; Europe: Copenhagen, Hambur! } \\
\text { \& Valencia. }\end{array}$ \\
\hline M3 [15] & $4^{\text {th }}$ & $\begin{array}{l}\text { Chandrasekaran } \\
\text { and Kumar }\end{array}$ & 1994 & Madras (a tropical site), India. \\
\hline M4 [16] & $1^{\text {st }}$ & Lam and Li & 1996 & Hong Kong, City University. \\
\hline M5 [17] & $3^{\text {rd }}$ & Miguel et al. & 2001 & $\begin{array}{l}8 \text { locations in the North Mediterranean Area: } \\
\text { South France, Spain \& Portugal. }\end{array}$ \\
\hline M6 [18] & $2^{\text {nd }}$ & Hawlader & 1984 & Singapore. \\
\hline M7 [20] & $4^{\text {th }}$ & Soares et al. & 2004 & Sao Paulo city, Brazil. \\
\hline M8 [21] & $3^{\text {rd }}$ & Jacovides et al. & 2006 & Athalassa (a semi-rural site), Cyprus. \\
\hline
\end{tabular}


Table 2. Statistical parameters of the present correlation with the measured data

\begin{tabular}{|c|c|c|c|c|c|}
\hline$r$ & MBE(\%) & MABE(\%) & MPE(\%) & MAPE(\%) & RMSE(\%) \\
\hline 0.885 & 0.005 & $6.20(<19.2)$ & 6.24 & $21.44(<65)$ & $8.0(<19.2)$ \\
\hline
\end{tabular}

Table 3. Best and worst values of the statistical comparison.

\begin{tabular}{|c|c|c|}
\hline Parameter & Best Value & $\begin{array}{l}\text { Worst } \\
\text { Value }\end{array}$ \\
\hline$r$ & 0.975 [M4] & 0.932 [M1] \\
\hline MBE (\%) & 6.52 [M7] & 13.63 [M1] \\
\hline MABE & 9.20 & 14.88 [M5] \\
\hline MPE (\%) & 15.99 [M7] & 45.82 [M4] \\
\hline MAPE & 27.51 [M7] & 45.82 「M4] \\
\hline RMSE & 11.55 [M7] & 18.97 [M1] \\
\hline
\end{tabular}

\section{REFERENCES}

[1] Panwar, N.L., Kaushik, S.C. and Kothari, S. Role of renewable energy sources in environmental protection: a review. Renewable and Sustainable Energy Reviews, 15(3):1513-1524, 2011.

[2] Hernandez, R.R., Easter, S.B., Murphy-Mariscal, M.L., Maestre, F.T., Tavassoli, M., Allen, E.B., Barrows, C.W., Belnap, J., Ochoa-Hueso, R., Ravi, S. and Allen, M.F. Environmental impacts of utility-scale solar energy. Renewable and Sustainable Energy Reviews, 29:766779, 2014.

[3] Mekhilef, S., Saidur, R. and Safari, A. A review on solar energy use in industries. Renewable and Sustainable Energy Reviews, 15(4):1777-1790, 2011.

[4] Eicker, U. Solar Technologies for Buildings. John Wiley \& Sons, 2006.

[5] Al-Najjar, H. M. T. Electric, heating and cooling yields of solar collectors for different atmospheric conditions and tilt angles. International Journal of Computer Applications, 141(10):1-10, May 2016.

[6] Bakirci, K. Models for the estimation of diffuse solar radiation for typical cities in Turkey. Energy, 82:827838, 2015.

[7] Liu, B.Y. and Jordan, R.C. The interrelationship and characteristic distribution of direct, diffuse and total solar radiation. Solar Energy, 4(3):1-19, 1960.

[8] Wong, L.T. and Chow, W.K. Solar radiation model. Applied Energy, 69 (3):191-224, 2001.

[9] Khorasanizadeh, H. and Mohammadi, K. Diffuse solar radiation on a horizontal surface: Reviewing and categorizing the empirical models. Renewable and Sustainable Energy Reviews, 53:338-362, 2016.

[10] Boland, J., Scott, L. and Luther, M. Modeling the diffuse fraction of global solar radiation on a horizontal surface. Environmetrics, 12:103-116, 2001.

[11] Orgill, J.F. and Hollands, K.G.T. Correlation equation for hourly diffuse radiation on a horizontal surface. Solar Energy, 19:357-359, 1977.

[12] Erbs, D.G., Klein, S.A. and Duffie, J.A. Estimation of the diffuse radiation fraction for hourly, daily and monthly average global radiation. Solar Energy, 28(4): 293-302, 1982.
[13] Reindl, D.T., Beckman, W.A. and Duffie, J.A. Diffuse fraction correlations. Solar Energy, 45(1):1-7, 1990.

[14] Karatasou, S., Santamouris, M. and Geros, V. Analysis of experimental data on diffuse solar radiation in Athens, Greece, for building applications. International Journal of Sustainable Energy, 23:1-11, 2003.

[15] Chandrasekaran, J. and Kumar, S. Hourly diffuse fraction correlation at a tropical location. Solar Energy, 53(6):505-510, 1994.

[16] Lam, J.C. and Li, D.H. Correlation between global solar radiation and its direct and diffuse components. Building and Environment, 31(6):527-535, 1996.

[17] De Miguel, A., Bilbao, J., Aguiar, R., Kambezidis, H. and Negro, E. Diffuse solar irradiation model evaluation in the north Mediterranean belt area. Solar Energy, 70(2):143-153, 2001.

[18] Hawlader, M.N.A. Diffuse, global and extra-terrestrial solar radiation for Singapore. International Journal of Ambient Energy, 5(1):31-38, 1984.

[19] Oliveira, A.P., Escobedo, J.F., Machado, A.J. and Soares, J. Correlation models of diffuse solar-radiation applied to the city of Sao Paulo, Brazil. Applied Energy, 71:59-73, 2002.

[20] Soares, J., Oliveira, A.P., Božnar, M.Z., Mlakar, P., Escobedo, J.F. and Machado, A.J. Modeling hourly diffuse solar-radiation in the city of São Paulo using a neural-network technique. Applied Energy, 79(2):201214, 2004.

[21] Jacovides, C.P., Tymvios, F.S., Assimakopoulos, V.D. and Kaltsounides, N.A. Comparative study of various correlations in estimating hourly diffuse fraction of global solar radiation. Renewable Energy, 31(15):24922504,2006

[22] Duffie, J.A., Beckman, W.A. Solar Engineering of Thermal Processes. John Wiley \& Sons, 2006.

[23] Iqbal, M. An Introduction to Solar Radiation. Elsevier, 2012.

[24] Robinson, N. and Stoch, L. Sky radiation measurement and corrections. Journal of Applied Meteorology, 3(2):179-181, 1964.

[25] Steven, M.D. and Unsworth, M.H. Shade-ring corrections for pyranometer measurements of diffuse solar radiation from cloudless skies. Quarterly Journal of 
the Royal Meteorological Society, 106(450):865-872, 1980.

[26] Stanhill, G. Observations of shade-ring corrections for diffuse sky radiation measurements at the Dead Sea. Quarterly Journal of the Royal Meteorological Society, 111(470):1125-1130, 1985.

[27] Ineichen, P., Gremaud, J.M., Guisan, O. and Mermoud, A. Study of the corrective factor involved when measuring the diffuse solar radiation by use of the ring method. Solar Energy, 31(1):113-117, 1983.

[28] Batlles, F.J., Olmo, F.J. and Alados-Arboledas, L. On shadow band correction methods for diffuse irradiance measurements. Solar Energy, 54(2):105-114, 1995.
[29] De Oliveira, A.P., Machado, A.J. and Escobedo, J.F. A new shadow-ring device for measuring diffuse solar radiation at the surface. Journal of Atmospheric and Oceanic Technology, 19(5):698-708, 2002.

[30] http://renewable.eastwestin.com/solar/sensors/shadowband.php.

[31] Coulson, K. Solar and Terrestrial Radiation: Methods and Measurements. Elsevier, 2012.

[32] Walpole, R.E., Myers, R.H., Myers, S.L. and Ye, K. Probability and Statistics for Engineers and Scientists. (Vol. 5). Macmillan, 1993. 